Таким образом, учитывая довольно жесткие критерии оправдываемости и достаточно большую заблаговременность, можно говорить о перспективности детализированного долгосрочного прогнозирования экстремумов метеорологических величин и хода элементов погоды в течение месяца.

Имеющаяся информационная база и программное обеспечение позволяют решать аналогичные задачи для сопредельных регионов.

Работа выполнена при финансовой поддержке Научной программы Министерства образования РФ «Университеты России» проект 8.5.9 «Метод и автоматизированная технология долгосрочного прогноза сильных осадков теплого периода» (грант УР.08.01.030).

\section{Библиографический список}

1. Мартазинова В.Ф., Сологуб Т.А. Определение квазипериодичности атмосферных процессов на Северном полушарии с помощью метода «плавающий аналог» // Тр. УкрНИГМИ. 1986. Вып. 219. С. 37-42.

2. Морозова С.В., Пужлякова Г.А. Эталонные поля давления интенсивных волн тепла и холода летом и зимой в Саратовской области // Анализ и прогноз гидрометеорологических элементов. Вопросы охраны атмосферы. Пермь, 1997. C. 25-30.

3. Морозова С.В., Полянская Е.А. К вопросу прогноза экстремумов метеорологических величин // Перспективы развития Волжского региона: Материалы Всерос. заочной конф. Тверь, 2003. С. 69-70.

\title{
ИЗМЕНЕНИЕ ЭТНИЧЕСКОГО СОСТАВА НАСЕЛЕНИЯ ОБЛАСТИ И ТОЛЕРАНТНОСТЬ СТУДЕНТОВ САРАТОВСКОГО ГОСУНИВЕРСИТЕТА
}

\section{С.В.Уставщикова}

Саратовский государственный университет, кафедра экономической географии E-mail: Reena.1.@yandex.ru

В статье рассмотрены изменения в этническом составе населения Саратовской области за 1989-2002 годы. Выявлена роль этнической миграции в данных изменениях. Отмечается рост в области народов Кавказа и Средней Азии. Изучение отношения к мигрантам выявило: довольно высокий потенциал толерантности студентов к данной категории населения; проявляется беспокойство по поводу конкуренции за рабочие места; возможность конфликта на «поведенческой» основе, неприемлемой в принимающем обществе с мигрантами из республик Закавказья; обеспокоенность демографической проблемой в РФ, миграционной политикой в стране.

Change of Ethnic Composition of the Population of the Region, and Tolerance of the Students of the Saratov State University

\section{S.V. Ustavschikova}

In the article change of the ethnic composition of the popularity of the Saratov region at the period from 1989 to 2002 are considering. The author shows as the role of the ethnic migration in given changes. In the region a number of people from the Caucasuc and Central Asia are growing. It is revealed, that: students are rather tolerant to emigrants; they are worried about the competition for job vacancy; conflict at the cultural ground is possible; they worried about demographical situation in the Russian Federation and its emigration policy.

В Саратовской области проживают более 110 этносов. Это результат исторического процесса заселения и освоения Саратовской земли, этнических процессов (этнического разделения и этнического объединения), этнической дифференциации

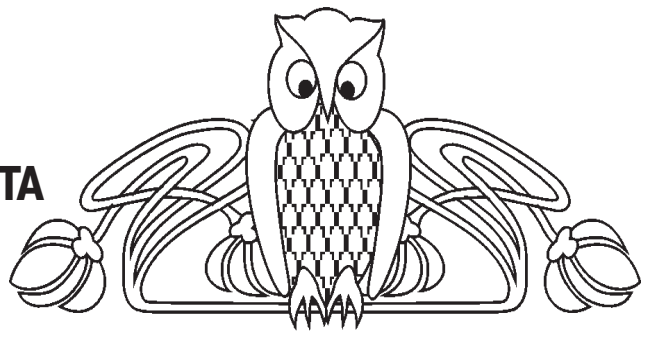

естественного воспроизводства и современных миграционных процессов.

Саратовская область является одним из принимающих мигрантов регионов России. По оценке областной миграционной службы, с конца 1990-х гг. по 2005 г. в Саратовскую область прибыло примерно 260 тыс. человек, что составляет почти $10 \%$ от численности населения области. Это достаточно большой показатель с точки зрения влияния миграции на все сферы жизнедеятельности территории, в том числе и на сферу межнациональных отношений.

Область привлекательна для мигрантов, она обладает большим производственным и научным потенциалом, развитой инфраструктурой. Привлекательность губернии обусловлена также относительной социально-политической стабильностью, комфортными климатическими условиями, значительным потенциалом для расселения населения в сельской местности (низкой плотностью сельского населения, значительным числом уже опустевших населенных пунктов - по переписи 2002 г. их 60, а также находящихся на грани исчезновения).

Складывающаяся демографическая ситуация в области, как и в целом по стране, объективно требует дополнительного привлечения трудовых ресурсов для обеспечения экономики региона. Население области сокращается. Если на момент переписи 2002 г. численность населения составляла 2668,3 тыс. человек, то на начало 2005 г. - уже 2625,7 тысяч. При этом, согласно данным статистики, после пика миграции из новых независимых 
государств в начале 1990-х гг. естественная убыль населения области уже не покрывается его миграционным приростом, который имеет тенденцию к снижению. За 2004 г. естественная убыль населения составила 19430 человек, а отраженный в статистике миграционный прирост - всего 836 человек. Однако, по оценкам экспертов, реальное количество мигрантов на территории области значительно превышает данные официальной статистики.

Если рассматривать официальные данные по странам прибытия, то с территории Азербайджана, Армении, Казахстана, Киргизии, Узбекистана прибыло лиц больше, чем уехало. Таджикистан тоже достаточно активно поставляет мигрантов. Большинство мигрантов стремятся закрепиться в городской местности, причем приоритетное положение занимают крупные многопрофильные города: Саратов (в котором проживает около трети всех прибывших в область), Балаково, Энгельс, где достаточно развита рыночная инфраструктура жилья, существует широкий рынок труда. Далее следуют такие города, как Красноармейск, входящий в саратовскую агломерацию, Аткарск, Пугачев, Ртищево, Маркс.

Официальная статистика свидетельствует, что за счет миграции наибольший прирост численности населения области наблюдался среди русских. Второе место занимают украинцы. На третьем месте армяне, на четвертом казахи и азербайджанцы, на пятом татары. Прирост численности остальных этнических групп весьма незначительный либо отрицательный. Такой этнический состав миграционного пополнения населения области объясняется в значительной мере тем, что основные потоки миграции идут в Саратовскую область из Закавказья, Средней Азии и Северного Кавказа. Не в последнюю очередь это связано с географическим положением области, ее территориальной близостью и транспортной доступностью для этих регионов.

Такой национальный состав миграционного прироста населения вряд ли способен скольконибудь серьезно повлиять на этническую картину Саратовской области, которая представлена 110 национальностями. Однако некоторые изменения необходимо отметить: рост численности и доли в населении армян, азербайджанцев; сокращение немцев, евреев, что связано именно с миграционной активностью данных народов.

Тем не менее нельзя забывать, что официально регистрируемая миграция составляет в Саратовской области, как и во многих других регионах России, лишь надводную часть айсберга. Гораздо больший миграционный приток остается невидимым из-за нелегального положения мигрантов. И в этой части притока доля русских, как правило, значительно меньше. Это создает предпосылки для усиления этнической составляющей антимигрантских настроений в обществе. Подавляющую часть нелегальных мигрантов в Саратовской области составляют выходцы из стран СНГ, большинство из которых (60-80\%) приезжает на заработки и является трудовыми мигрантами. Среди них основная категория - сезонники. Тех же, кто хочет остаться, стремится получить вид на жительство, гражданство, сравнительно мало. В числе нелегальных мигрантов становятся все более заметны таджики и узбеки.

Одна из заметных этнических групп нелегальных мигрантов образовалась в результате массового переселения курдов из Краснодарского края на территорию Саратовской области (72 человек в 1989 г.; 2268 - в 2002 г.). Не получив возможности урегулировать свое правовое положение там, они переселяются сюда и, не получив легального статуса, остаются все в той же категории нелегальных мигрантов. Расселились они компактно в Озинском (1135 чел.) и Дергачевском (243 чел.) районах. Численность корейцев в области возросла с 545 человек (1989 г.) до 2533 (2002 г.). Вьетнамских, китайских мигрантов в регионе почти нет.

Как же изменился этнический состав населения области за 1989-2002 годы?

Основной национальностью в регионе являются русские, их доля в населении возросла в результате миграционного притока из стран СНГ и Балтии. Абсолютная численность русских сократилась в результате естественной убыли (превышения смертности над рождаемостью). Еще 16 народов, проживающих в области, имеют каждый численность более 3000 человек, т. е. $0,1 \%$ и более во всем населении. Все другие народы, а их около 100 , малочисленны и составляют $2 \%$ от населения области (табл. 1).

Непрерывное изменение доли различных народов в населении области объясняется их неодинаковым естественным приростом (фактически он сводится к разному уровню рождаемости, так как различия в уровне смертности невелики) и процессами естественной ассимиляции (главным образом в результате смешанных браков и перехода на другой язык). Так, за межпереписной период произошло значительное сокращение численности украинцев в области. В большей мере это связано именно с ассимиляционными процессами, чем с оттоком украинцев из Саратовской области. Украинцы в 1989 г. были вторым по численности народом в нашем крае. Число назвавших себя украинцами сократилось на 44\% к переписи 2002 года. Численность и доля казахского населения напротив возросли, что объясняется не только миграционным притоком (который не столь значителен), но и естественным приростом у казахов. Этот народ стал вторым по численности в населении области. Количество и доля татар возросли, в частности в результате переезда татар из Казахстана, государств Средней Азии. Это четвертый по численности народ в области.

На численность других крупных народов области, назвавших себя мордвой, чувашами, 
Крупнейшие по численности населения народы области [1]

\begin{tabular}{|l|c|c|c|c|c|}
\hline \multicolumn{1}{|c|}{ Народы } & $\begin{array}{c}\text { Численность, } \\
\text { чел. (1989 г.) }\end{array}$ & $\begin{array}{c}\text { Процент от все- } \\
\text { го населения }\end{array}$ & $\begin{array}{c}\text { Численность, } \\
\text { чел. (2002 г.) }\end{array}$ & $\begin{array}{c}\text { Процент от все- } \\
\text { го населения }\end{array}$ & $\begin{array}{c}\text { 2002 г., про- } \\
\text { цент от 1989 г. }\end{array}$ \\
\hline Русские & 2298992 & 85,6 & 2293129 & 85,9 & 99,7 \\
\hline Казахи & 73428 & 2,7 & 78320 & 2,9 & 106,7 \\
\hline Украинцы & 101832 & 3,8 & 67257 & 2,5 & 66 \\
\hline Татары & 52867 & 2,0 & 57577 & 2,2 & 108,9 \\
\hline Армяне & 6404 & 0,2 & 24976 & 0,9 & 390 \\
\hline Мордва & 23381 & 0,9 & 16523 & 0,6 & 74,9 \\
\hline Азербайджанцы & 10610 & 0,4 & 16417 & 0,6 & 154,7 \\
\hline Чуваши & 20613 & 0,8 & 15956 & 0,6 & 77,4 \\
\hline Белорусы & 17771 & 0,7 & 12675 & 0,5 & 71,3 \\
\hline Немцы & 17068 & 0,6 & 12093 & 0,4 & 70,8 \\
\hline Чеченцы & 5963 & 0,2 & 8515 & 0,3 & 142,8 \\
\hline Лезгины & 4952 & 0,2 & 5308 & 0,2 & 107,2 \\
\hline Башкиры & 4085 & 0,1 & 3988 & 0,1 & 97,6 \\
\hline Марийцы & 5318 & 0,2 & 3983 & 0,1 & 74,9 \\
\hline Молдаване & 4535 & 0,1 & 3840 & 0,1 & 84,7 \\
\hline Евреи & 8054 & 0,3 & 3428 & 0,1 & 42,6 \\
\hline Другие народы & 28598 & 1,2 & 44325 & 2,0 & 155,0 \\
\hline
\end{tabular}

белорусами, башкирами, молдаванами, марийцами в большей мере влияют ассимиляционные процессы и процессы естественного воспроизводства, чем миграционные. Изменение численности армян, азербайджанцев, чеченцев, лезгин, немцев, евреев - результат миграционных процессов 1990-х годов. Причем если у первых четырех народов миграционный прирост был с положительным знаком, то немцы и евреи вы- езжали из области преимущественно в страны дальнего зарубежья.

Миграция оказала определенное влияние на динамику численности населения многих районов области и населенных пунктов, половозрастную, социальную, национальную структуры населения. Для области стал характерен значительный миграционный прирост населения. Это хорошо иллюстрируют данные табл. 2.

Таблиияа 2

Миграционное движение населения Саратовской области, тыс. чел. [2]

\begin{tabular}{|c|c|c|c|c|c|}
\hline \multirow{2}{*}{ Миграция } & \multirow{2}{*}{ Годы } & \multicolumn{2}{|c|}{ Прибывшие } & \multicolumn{2}{|c|}{ Выбывшие } \\
\hline & & Город & Село & Город & Село \\
\hline \multirow{5}{*}{ Внутрирегиональная } & 1990 & 29,3 & 21,7 & 26,4 & 24,6 \\
\hline & 1992 & 19,1 & 17,6 & 23,7 & 13,0 \\
\hline & 1995 & 21,3 & 12,7 & 20,6 & 13,4 \\
\hline & 1999 & 17,5 & 11,3 & 17,4 & 11,4 \\
\hline & 2002 & 16,7 & 8,4 & 15,2 & 9,9 \\
\hline \multirow{5}{*}{ Межрегиональная } & 1990 & 19,5 & 11,3 & 18,0 & 10,4 \\
\hline & 1992 & 15,9 & 7,6 & 18,0 & 6,6 \\
\hline & 1995 & 17,5 & 5,8 & 15,0 & 6,8 \\
\hline & 1999 & 13,3 & 5,2 & 11,1 & 4,9 \\
\hline & 2002 & 26,6 & 12,1 & 25,2 & 14,3 \\
\hline \multirow{5}{*}{ Со странами СНГ и Балтии } & 1990 & 11,6 & 9,5 & 7,6 & 4,9 \\
\hline & 1992 & 15,7 & 12,2 & 5,8 & 3,2 \\
\hline & 1995 & 13,7 & 7,9 & 2,6 & 1,8 \\
\hline & 1999 & 7,0 & 5,0 & 1,4 & 1,0 \\
\hline & 2002 & 3,5 & 1,2 & 0,7 & 0,6 \\
\hline \multirow{5}{*}{ Со странами дальнего зарубежья } & 1990 & 1,2 & 0,1 & 1,3 & 0,7 \\
\hline & 1992 & 1,0 & 0,1 & 1,8 & 0,6 \\
\hline & 1995 & 0,1 & 0,0 & 1,1 & 1,5 \\
\hline & 1999 & 0,0 & 0,0 & 1,0 & 1,1 \\
\hline & 2002 & 0,0 & 0,0 & 0,8 & 1,1 \\
\hline
\end{tabular}


В рамках межобластной миграции определяющее значение для Саратовской области имеет обмен населением с областями Поволжья и ближайшими регионами: Центрально-Черноземным, Центральным, Северо-Кавказским. Среди административно-территориальных единиц Северо-Кавказского региона основной миграционный обмен в 1990-е гг. шел с Чеченской Республикой, причем в начале периода проходил интенсивный отток этнических чеченцев из области. На территории области они проживали, как правило, в небольших поселениях (на 3-5 семей), занимаясь животноводством, и выезжали в Чечню целыми семьями. С 1994-1995 гг. фиксировался значительный приток в область как русскоязычного населения, так и чеченцев. Кроме этого, область принимала мигрантов из района Дальнего Востока, Западной Сибири. Тем не менее начиная с 1990 г. основной миграционный прирост населения области складывался за счет межреспубликанского обмена (страны СНГ и Балтии сегодня - табл. 3).

Численность коренных народов стран СНГ и Балтии в России

Таблииа 3 и Саратовской области (2002 г.) [1]

\begin{tabular}{|l|c|c|c|}
\hline \multicolumn{1}{|c|}{ Народ } & Проживает в РФ, тыс.чел. & $\begin{array}{c}\text { Проживает в Саратовской } \\
\text { обл., чел. }\end{array}$ & $\begin{array}{c}\text { Доля в Саратовской обл. от } \\
\text { РФ, } \%\end{array}$ \\
\hline Азербайджанцы & 621 & 16417 & 2,6 \\
\hline Армяне & 1130 & 24976 & 1,5 \\
\hline Белорусы & 815 & 12675 & 1,2 \\
\hline Грузины & 198 & 2444 & 11,9 \\
\hline Казахи & 655 & 78320 & 1,0 \\
\hline Киргизы & 32 & 311 & 0,8 \\
\hline Латыши & 29 & 231 & 1,1 \\
\hline Литовцы & 45 & 502 & 2,2 \\
\hline Молдаване & 172 & 3840 & 1,2 \\
\hline Таджики & 120 & 1468 & 1,7 \\
\hline Туркмены & 33 & 563 & 1,7 \\
\hline Узбеки & 123 & 2140 & 2,3 \\
\hline Украинцы & 2943 & 67257 & 1,0 \\
\hline Эстонцы & 28 & 290 & \\
\hline
\end{tabular}

Наибольшей пестротой национального состава отличаются города области. Доля русских везде очень велика, выше всего она в городах Правобережья: от 95,8\% в Ртищеве до 89\% в Калининске. В областном центре русские составляют 90\% населения, и 38\% всех русских, проживающих в области, сконцентрированы в Саратове. В Левобережье доля русских в городах ниже - максимальна она в г. Энгельсе $(88,4 \%)$, минимальна в г. Новоузенске (79,9\%). Русских можно назвать городскими жителями. В Саратове самые многочисленные после русских следующие национальности: украинцьь (1,8\% от всего населения города, $23,6 \%$ от всех украинцев области), maтары (1,7\% и $26,6 \%$ от всех татар), армяне ( $1 \%$ и $36,6 \%$ от всех армян), азербайджанцыь (0,7\% и $38,9 \%$ от всего народа), казахи (0,6\% от населения города и $6,4 \%$ от всех казахов области, незначительна их доля и в других городах - это сельские жители), мордва (20,8\% от всей мордвы), белорусы (24,6 \%), чува- ши (12,8\%), немц̧ь (12,9\% всех немцев области). Евреи по преимуществу живут в городах, $81 \%$ всех евреев области сосредоточены в Саратове.

Из других народов в городах значительна доля украинщев: в г. Энгельсе $(3,4 \%$ населения города, 9,9\% всех украинцев), пос. Приволжский (украинцы составляют 6,7\% населения всего поселка), г. Калининске (5,7\%), г. Марксе (3,1\%), г. Аткарске (2,7\%), г. Красноармейске (2,2\%), г. Балаково (2,2\%). Казахи проживают в г. Новоузенске (12,5\% от населения города), г. Ершове $(4,0 \%)$, в г. Энгельсе (0,6\% населения города, но 5,1\% всех казахов области); mamapb - г. Энгельсе (2,7\%, проживает 9,1\% всех татар области), г. Балаково (1,7 \% от населения города и 5,9\% от татар), г. Пугачеве $(6,6 \%)$, г. Ершове $(3,8 \%)$; мордва г. Энгельсе $(0,6 \%$ населения крупного города, $8 \%$ от всей мордвы), г. Балаково (0,5\% и $6,2 \%$ от народа), г. Петровске $(2,5 \%)$; чуваши - г. Балаково $(0,6 \%$ и 7,2\% чувашей $)$ белорусы - г. Энгельсе 
(0,6 \% населения города и 9,2 \% белорусов), г. Балаково (0,5\% и 8,5\% соответственно); армяне, кроме Саратова, значительную долю составляют в таких городах как Энгельс $(0,5 \%$ и 4,3\% армян области), Ершов (4,1\%), Аркадак $(1,2 \%)$, Вольск $(1,0 \%) ;$ немщы - в г. Энгельсе $(0,6 \%$ от населения города, 6,8\% немцев области), в г. Марксе $(1,4 \%$ населения).

Представители большинства проживающих в области народов есть практически в каждом из 38 районов. У наиболее многочисленных и давно проживающих в области народов сложилась своя география расселения. Так, русских больше проживает в Правобережье, где их доля составляет от $72,6 \%$ в Петровском районе до $95,7 \%$ в Турковском. В Левобережье их удельный вес ниже-от $40,9 \%$ в Александрово-Гайском районе до 79,8\% в Пугачевском. И только в Краснопартизанском, Ивантеевском и Духовницком районах русских более $80 \%$. Духовницкий район - самый русский район Левобережья, доля русских составляет $91,1 \%$ от населения района.

Казахи - второй по численности населения народ в области. Проживают они на юго-востоке Заволжья. В Александрово-Гайском районе их доля в населении составляет 52,1\% (11,8\% от всех казахов). Значительно представительство казахов в Новоузенском 25,1\% (10,9\% всех казахов области), Питерском - 23,9\%, Дергачевском - 20,8\%, Озинском, Ровенском, Краснокутском, Перелюбском, Марксовском, Федоровском, Советском (в каждом более $10 \%$ от всего населения) районах.

Украинщьы - третья по численности населения национальность в области. Наибольшая доля украинцев в населении следующих районов: Самойловском, Калининском, Энгельсском, Краснокутском, Федоровском и Ершовском.

Татарские, мордовские, чувашские села можно встретить по обеим сторонам Волги. Так, наибольшая численность татар в Дергачевском районе $(17,8 \%$ от всего населения района и $8 \%$ от татар, проживающих в области), много их в Базарно-Карабулакском (8,2\% и 5,2\% соответственно), Ершовском (4,4\% и 3,8\%), Петровском (8,7\% и $2,5 \%$ районах. Мордва проживает в основном в Петровском (10,6\% от населения района и 8,6\% от всей мордвы области), Хвалынском $(5,4 \%$ и $4,2 \%$ соответственно), Энгельсском (2,3\% и 6,3\%), Балтайском (2,7\%), Татищевском $(2,6 \%)$ районах. Чуваши-в Базарно-Карабулакском (7,3\% во всем населении и $16,7 \%$ от всех чувашей), Балаковском $(2,2 \%$ и $2,7 \%)$, Вольском $(2,9 \%$ и $5,4 \%)$, Пугачевском $(1,7 \%$ и $2,5 \%)$.

Армяне, кроме областного центра и больших городов, проживают и в Правобережье, и в Заволжье. Наибольшая концентрация их в Балтайском районе, где они составляют 9\% в населении района, что соответствует 5\% армян, живущих в области. Это новое явление в расселении армян сложилось в результате миграции последних лет. В Ершовском районе они составляют 2,4\% населе- ния (4,8\% всех армян области). От 1,5 до 2\% они составляют в населении Татащевского, Екатериновского, Калининского, Краснокутского районов. В сельских районах - Аткарском и Новобурасском значительно представительство азербайджанского народа (2,4\% и 2,8\% соответственно).

Немйы проживают в Левобережье. Наибольшее их число в Марксовском (5,2\% от населения района и 14,7\% немцев), Энгельсском (2,5 и 9,2\% соответственно), Ровенском (4 \% и 6,1\%)районах. В Правобережье наиболее значительна их доля в Красноармейском районе - 2,6\% во всем населении. Белорусы рассеяны по всем районам области.

От 1 до 2,3\% в численности населения чеченцъь представляют в таких районах Правобережья, как Екатериновский $(5,1 \%$ от всех чеченцев области), Калининский $(5,5 \%)$, Вольский $(3,7 \%)$, Лысогорский (3,5\% всех чеченцев). Лезгины проживают во всех районах, наиболее значительны по численности они в Красноармейском, Марксовском, Ивантеевском, Калининском, Ершовском, Перелюбском районах (от 3,5 до 4,7 \% от всех лезгин в каждом).

Перелюбский район - «башкирский», 36,7\% всех башкир области проживает здесь, что составляет 7,6\% от населения района. От $1 \%$ до 2,3\% в населении Краснокутского, Пугачевского и Балаковского районов составляют марийщ̧ь (от 4,4 до $11,9 \%$ от марийцев области). Таковы основные географические различия в национальном составе населения нашей области.

В Советском Союзе этничность приобрела институциализацию. Институциализация этничности, а тем самым и невольная сегрегация населения по этническому признаку, нашла выражение в этнофедерализме, при котором некоторые этнические группы - не просто субъекты (культурной) идентичности, а субъекты (политического) суверенитета. Поэтому в настоящее время этносы, имеющие свою государственность за пределами Российской Федерации, рассматриваются как «чужие» для большинства народов, населяющих нашу страну, несмотря на то, что большинство из них родились и проживали в России, имеют российское гражданство. Это положение может стать причиной этнических конфликтов, в частности, и на территории Саратовской области.

В нашей области в августе-сентябре 2002 г. было проведено социологическое обследование на тему «Отношение населения Саратовской области к миграции и мигрантам». Исследование осуществлялось Центром изучения проблем вынужденной миграции в СНГ в 4 субъектах Российской Федерации (Нижегородской, Оренбургской и Саратовской областях, а также в Удмуртии) и охватило в общей сложности более 1000 местных жителей. В Саратовской области было опрошено 300 респондентов: 220 местных жителей, в том числе 150 человек в Саратове и 70 человек в сельской местности, а также 80 студентов (по 40 
человек с гуманитарных и технических факультетов, и в каждой группе по 20 человек со старших и младших курсов).

Опрос показал: 1) область испытывает очень большое миграционное давление; 2) городских жителей беспокоит приток с Кавказа; 3) сельских жителей кавказские мигранты волнуют меньше, зато более половины из них считают, что основной приток в область идет из Казахстана [2].

Такое распределение ответов отражает реальное расселение соответствующих диаспор на территории Саратовской области. Казахи - это сельские жители, армяне, азербайджанцы - городские. Интересно отметить, что студенты, будучи городскими жителями, тем не менее, как и селяне, заметно выделяют поток из Казахстана. Это может являться индикатором активного использования жителями Казахстана учебного канала миграции в Россию.

Респондентам в ходе опроса был задан вопpoc: к мигрантам каких национальностей они относятся положительно, отрицательно и крайне отрицательно? Опрос показал: 1) антимигрантские настроения большинства опрошенных; 2) эти настроения в очень большой мере имеют этническую окраску, практически полностью представленную антикавказской компонентой, и можно даже говорить о наличии кавказофобии; 3) на втором месте - представители народов среднеазиатского региона. Главной будирующей группой мигрантов из Центральной Азии оказались таджики и таджикские цыгане, в меньшей степени узбеки и казахи [2].

Осенью 2005 г. нами было проведено изучение толерантности студентов СГУ. В рамках чтения курсов «Демография», «Этнография и география религий», «География населения с основами демографии» в студенческих группах разных специальностей были проведены беседы и опросы по проблемам этнической толерантности. Исследование проводилось с использованием качественных методов в социологии [3]. Это исследование стало возможно в результате большого интереса студентов к изучаемому материалу (демографическая проблема в Российской Федерации, миграционная политика в стране, рост этнического фактора в конфликтах различных стран мира, в России), сложившихся доверительных отношений между преподавателем и студентами.

По результатам исследования можно сделать следующие выводы.

1. Подавляющее число студентов, часто не имея представления о численности мигрантов в области, тем не менее считают, что мигрантов очень много. При этом ими не разделяются мигранты, прибывающие на постоянное место жительства, и трудовые - сезонные мигранты.

2. Полиэтничное по составу студенчество СГУ обладает довольно высоким потенциалом толерантности по отношению к мигрантам.
3. Толерантность по отношению к тому или иному народу часто зависит от таких факторов, как принадлежность к коренным российским народам, длительность совместного проживания в пределах области, а для представителей диаспор ближнего и дальнего зарубежья - местонахождение исторической родины и ее отношение с Россией. Важную роль играют также общий культурный уровень того или иного народа и преимущественный род занятий его представителей в России.

Так, на толерантность к казахам влияют, повидимому, и длительный период совместного проживания, и характер труда в сельской местности. Таджики, - занятые в основном в строительстве, также «менее заметны» для студенчества. Это чаще все же трудовые мигранты.

В сознании местных жителей, особенно тех, кто относит себя к группе «славяне и представители других европейских народов», сложился негативный образ «кавказца». В качестве характерных черт, образующих стереотип кавказских народов, выступают «агрессивность», «вспыльчивость», «хитрость», «высокомерие», «навязчивость», «лицемерие». Источник антикавказских настроений студентов связан с поведением кавказцев, которое выглядит дерзким и вызывающим, нарушает нормы, принятые в российском обществе. Отмечается рост кавказцев (армян) в вузах Саратова. Проявляется беспокойство по поводу конкуренции за рабочие места.

Мигранты (азербайджанцы, армяне) стремятся селиться по местническому признаку. В Саратове в настоящее время это менее заметно, чем, например, в Москве, однако тенденция к тому начинает прослеживаться. Так, азербайджанцев больше в Волжском и Кировском, а армян в Октябрьском и Кировском районах Саратова.

Студенты обладают информацией, которая поддерживается в СМИ, об общем тяжелом положении русских на постсоветском пространстве. В России же, и Саратовская область не исключение, процесс создания и деятельности этнических общественных организаций (Всероссийского азербайджанского конгресса с региональными отделениями, Армянского, Таджикского) имеет одну особенность, которую условно можно назвать идеализацией этничности. Каждая из организаций имеет целью защиту прав только «своих» мигрантов - этнических соотечественников, выдвигая на первый план, таким образом, национальную компоненту, а не гражданско-правовую. Подобная ситуация свидетельствует о все большем дроблении культурных пространств, транслируемых этническими группами; развивается этот процесс параллельно с дроблением культурного пространства России на обособленные национальные сегменты.

Необходимо отметить и антипатию большинства студентов к цыганам, что является следствием паразитарного способа существования части представителей этноса (попрошайничество, обман). 
4.Вопрос возможного обучения в СГУ иностранных студентов из стран дальнего зарубежья интересует и волнует многих студентов. Обучающиеся иностранцы «по-соседству»в Медицинском университете заметны. Высказывались следующие пожелания: «чтобы их не было слишком много», «после обучения необходим их отъезд на родину».

Такое настроение молодежи складывается в результате обеспокоенности высказываниями на самом высоком уровне и публикациями в СМИ, научных журналах на темы о «демографическом кризисе» в стране, который в основном касается воспроизводства славянских народов, об уменьшении доли русских в населении Российской Федерации, о том, что это приобрело характер устойчивой тенденции [4]. Большинство студентов понимают, что будет происходить дальнейший рост миграции в Россию, особенно из Закавказья, Средней Азии, Китая и других государств «ближнего» и «дальнего» зарубежья, этнически чуждых славянскому этносу народов.

Стремление к добрым отношениям с людьми разных национальностей, что прослеживается в высказываниях большинства студентов, сочетается с желанием сохранить собственную культурную идентичность. Жесткая позиция в отношении национальных проблем отнюдь не является следствием отрицания межнациональной толерантности. Она, по-видимому, и здесь можно согласиться со многими авторами, стоящими на схожих позициях, служит способом самозащиты в условиях сокращения и размывания восточнославянского ядра Российского государства [5]. Процесс должен быть двусторонним, что предполагает также и повышение толерантности мигрантов к принимающему обществу.

\section{Библиографический список}

1. Материалы Саратовского областного комитета по статистике: Статистический сб. Саратов, 2005. 171 с.

2. Витковская Г.С. Миграция и мигрантофобия в Приволжском регионе: Саратовская область // Миграционная ситуация в регионах России. Вып. 2. Приволжский федеральный округ / Под ред. Ж. Зайончковской. М., 2004. 201 с.

3. Ковалев Е.М., Штейнберг И.Е. Качественные методы в полевых социологических исследованиях. М., 1999. 384 с.

4. Руткевич М.Н. Воспроизводство населения и социально-демографическая ситуация в России // Социс. 2005. №7. C. 22-30.

5. Гаврилов Ю.А., Кофанова Е.Н., Мчедлов М.П., Шевченко А.Г. Сфера политики и межнациональные отношения в восприятии религиозных общностей // Там же. № 6. C. 56-70.

УДК 504 (470.44)

\section{ИЗУЧЕНИЕ ПРИРОДНЫХ И ТЕХНОГЕННЫХ ГЕОЭКОЛОГИЧЕСКИХ РИСКОВ НА ТЕРРИТОРИИ ГОРОДА САРАТОВА}

\section{В.К.Штырова, О.Е.Нестерова}

Саратовский государственный университет, кафедра геоморфологии и геоэкологии E-mail: Nesterova@sgu.ru

В статье рассматривается понятие геоэкологического риска, его виды. Приводится характеристика природно-техногенных процессов и проявлений факторов природного и техногенного рисков. Обосновывается возможность районирования территории города по степени проявления риска.

\section{Studying of Natural and Technogenic Geoecological Risks of the City Saratov}

\section{V.K.Shtyrova, O.E.Nesterova}

The concept of geoecological risk, its kinds is considered in article. The characteristic of natural-technogenic processes and display of factors of natural and technogenic risks is resulted. The opportunity of division into districts of territory of city on degree of display of risk is proved in article.

Как и в большинстве крупных городов, в Саратове быстро ухудшается качество окружающей

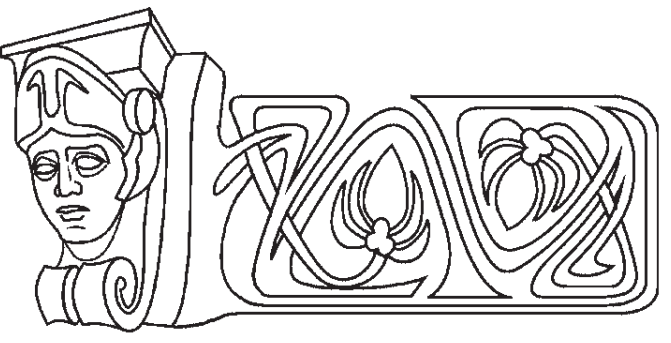

среды, повышается экологический и геоэкологический риск проживания людей вследствие неудержимого процесса урбанизации и активизации техногенного воздействия на природу. В результате происходит увеличение заболеваемости, смертности населения, ухудшение качества жизни.

Любой опасный природный процесс - это результат нарушения равновесного состояния, вызванного изменениями внешних воздействий со стороны атмосферы, литосферы, гидросферы или техносферы.

Геоэкологический риск определяется вероятностью развития нежелательных природных или природно-техногенных явлений в окружающей среде в результате активизации процессов, создающих угрозу людям, ухудшающих экологическую обстановку в городе и способствующих преждевременному износу и выходу из строя зданий и сооружений. Развитие факторов геоэкологичес- 